\title{
Reduction of cement content using graded aggregates in concrete production
}

\author{
Benjamin Okwudili Mama ${ }^{1}$, Chinedu Christian Asogwa ${ }^{1}$, Boniface Obi Ugwuishiwu ${ }^{2}$ and Samson \\ Nnaemeka Ugwu 2,* \\ ${ }^{1}$ Department of Civil Engineering, University of Nigeria, Nsukka. \\ ${ }^{2}$ Department of Agricultural and Bioresources Engineering, University of Nigeria, Nsukka, Nigeria.
}

Global Journal of Engineering and Technology Advances, 2021, 07(03), 125-135

Publication history: Received on 08 May 2021; revised on 13 June 2021; accepted on 16 June 2021

Article DOI: https://doi.org/10.30574/gjeta.2021.7.3.0083

\begin{abstract}
The aim of this project was to reduce cement content in concrete mixtures by changing the aggregate grading. For this purpose, concrete mixtures were made with aggregates having different shapes, textures, and grading. However, the workability of concrete mix depends on its paste volume, paste composition, and the type of aggregate used. Concrete testing was performed, and concrete properties including slump, compressive strength, and tensile splitting test were tested. The effect of aggregate shape on workability was evaluated by comparing one aggregate combination to another. It was found that the aggregate combination with $\mathrm{S} / \mathrm{A}=0.4 \mathrm{GR}-\mathrm{B}-\mathrm{CA}+\mathrm{NA}-\mathrm{A}-\mathrm{FA}$ had optimum workability properties and generally, GR-B-CA+NA-A-FA consistently had the highest workability, as well as the highest paste volume demand. This can be attributed to its poor grading as a result of the gaps in GR-B-CA content. Compared with NA-A-CA + NA-A-FA, it resulted in concrete mixtures with lower paste volume demand.
\end{abstract}

Keywords: Aggregate; Concrete; Graded; Cement; Workability

\section{Introduction}

Concrete is a mixture of cementitious (binding) material, aggregate, and water. Aggregate is the main constituent of concrete and commonly considered inert filler, which accounts for 60 to 80 percent of the volume and 70 to 85 percent of the weight of concrete [1,2,3]. Although aggregate is considered inert filler, it is a necessary component that defines the concrete's thermal and elastic properties and dimensional stability [2]. According to [4], aggregate is classified as two different types, coarse and fine. Coarse aggregate is usually greater than $4.75 \mathrm{~mm}$ (retained on a No. 4 sieve), while fine aggregate is less than $4.75 \mathrm{~mm}$ (passing the No. 4 sieve). Aggregate characteristics of shape, texture, and grading influence workability, finishability, bleeding, pumpability, cost and segregation of fresh concrete and affect strength, stiffness, shrinkage, creep, density, permeability, durability and on overall performance of fresh concrete [5].

Shape of the aggregate particles influences paste demand, placement characteristics such as workability and pumpability, strength and cost. Shape is related to sphericity and form (cubical, spherical, flat or elongated), angularity and roundness (Angular, subangular, subrounded, rounded, well-rounded) [6]. Methods used to measure the shape of aggregates are the elongation factor and flatness factor [2]. The shape can modify the strength of the concrete, as in the case where a thin, flat particle is oriented in the hardened concrete where outside stresses are introduced [7]. Flaky, elongated, angular, and rough particles have high voids and require more sand to fill voids and to provide workable concrete, thus increasing the demand for water; it also can affect the mobility of mixtures and contribute to harshness $[8,9]$. While that of fine aggregate affects workability, strength and durability of hardened concrete, cubical or spherical particles require less paste and less water for workability, lead also to better pumpability and finishability $[10,11]$.

\footnotetext{
* Corresponding author: Ugwu, Samson Nnaemeka Email: samnnaemeka.ugwu@unn.edu.ng

Department of Agricultural and Bioresources Engineering, University of Nigeria, Nsukka, Nigeria. 
Surface texture is the degree to which the surface may be defined as being rough or smooth (height of asperities) or coarse grained or fine grained (spacing between grains); roughness or rugosity (degree of surface relief) and the roughness factor (the amount of surface area per unit of dimensional or projected area) [7]. Natural aggregate has smooth texture than manufactured aggregates. The surface texture influences the workability, quantity of cement and bond between particles and the cement paste. Rough particles tend to provide stronger bond than smooth particles. As a result, rough particles tend to produce higher strengths [12] and tend to decrease shrinkage.

The gradation of an aggregate is the frequency of a distribution of the particle sizes of a particular aggregate. The size distribution or grading according to ASTM [13] divides aggregate in three categories; Coarse aggregate (retained by No. 4 sieve), Fine aggregate (passing No. 4 sieve and retained in No. 200 sieve) and Microfines (passing No. 200 sieve) [7]. Gradation plays an important role in the workability, segregation, and pumpability of the concrete. Construction and durability problems have been reported due to poor mixture proportioning and variation on grading [14]. According to Quiroga and Fowler [7], aggregate that blend with well-shaped, rounded, and smooth particles require less paste for a given slump than it blends with flat, elongated, angular, and rough particles. At the same time, uniform grading with proper amounts of each size result in aggregate blends with high packing and in concrete with low water demand. Other characteristics of aggregate that affect the performance of fresh and hardened concrete are Absorption, Mineralogy and coatings, Strength and stiffness, Maximum size, Specific gravity or relative density, Soundness and Toughness.

Aggregates in concrete is increased because cement is more expensive than aggregate, so using more aggregate reduces the cost of producing concrete and as well that most of the durability problems, e.g., shrinkage and freezing and thawing, of hardened concrete are caused by increased cement content [2]. Aggregates, on the other hand, reduce shrinkage and provide more volume stability. In optimizing aggregate gradation, the following methods had been used; Packing Density Method, [15], Surface Area [2], Power Chart (ACI 302-04; IM 532), Coarseness Factor Chart [9], Percent Retained, Iowa Dot "18-8" Chart [7] and ACI Mixture Design Method [2].

More so, cementitious and pozzolanic materials such as fly ash had been researched on as possible replacements for cement because cement products are main sources of carbon dioxide $\left(\mathrm{CO}_{2}\right)$ emissions, hence, reducing its usage should be a goal in concrete production. This work is therefore aimed at decreasing paste volume by varying aggregate with different properties (such as angularity, texture and grading), testing the effects of packing density and inter-particle friction by varying the types and gradations of the aggregates used.

\section{Material and methods}

To identify differences in the performance relating to material properties of concrete mixtures, two coarse aggregates were used, a well-rounded natural coarse aggregate represented as NA-A-CA and a cubical, angular granite crushed coarse aggregate represented as GR-B-CA and a well-rounded natural fine aggregate was tested, (river sand represented as NA-G-FA). Standard test methods were used to evaluate the properties of aggregates and performances of mortar and concrete mixtures. These test methods include.

\subsection{Aggregate characterization tests}

\subsubsection{Sieve analysis}

The test method described in ASTM [16] Standard Test Method for Sieve Analysis of Fine and Coarse Aggregates was used to determine the gradation of the fine and coarse aggregates. The sieve analysis of coarse and fine aggregates were performed using sieve sizes: $1^{\prime \prime}, 3 / 4 " 1 / 2 "$, 3/8" , Nọ4, Nọ8, Nọ16, Nọ30, Nọ50, Nọ100, Nọ200, sieve shaker, weighing balance, sieve cover and sieve pan.

\subsubsection{Specific gravity and water absorption of coarse and fine aggregate test}

The specific gravity and absorption capacity of the coarse aggregates was determined using ASTM [17] Standard Test Method for Density, Relative Density (specific gravity), and Absorption of Coarse aggregates. ASTM [18] Standard Test Method for Density, Relative Density (Specific Gravity), and Absorption of Fine Aggregate was used to determine the specific gravity and absorption capacity of the fine aggregates. Specific gravity and absorption are determined using equations 1 and 2 below.

The specific gravity (Gs) = $\frac{\text { weight of substance }}{\text { weight of water of the same volume }}-\quad-\quad-\quad-\quad 1$ 
The absorption capacity of the aggregate (W.A) $=\frac{(W 2-W 1-W 5)}{W 5} \mathrm{x} 100 \%-\quad-\quad 2$

Where $w_{1}, w_{3}, w_{4} w_{2}, \& w_{5}$ are as defined as weight of empty specific gravity bottle $w_{1}$, weight of surface dry previously soaked aggregate and specific gravity bottle $\mathrm{w}_{2}$, weight of bottle, aggregate and water $\mathrm{w}_{3}$, weight of bottle content was removed and filled with only water $\mathrm{w}_{4}$ then the aggregate oven dried for 24 hours and weighed $\mathrm{w}_{5}$.

\subsubsection{Bulk unit weight of fine and coarse aggregate test}

The bulk density of the aggregates was determined following ASTM [19] Standard Test Method for Bulk Density (Unit Weight) and Voids in Aggregates. The test was performed on both fine and coarse aggregates separately and then on combination. The combinations included the different proportions of aggregates. Cylindrical container, tamping rod, weighing balance were the apparatus used.

\subsubsection{Moisture content test}

The moisture content of the coarse and fine aggregate was determined according to BS standard using moisture content can, electric oven, weighing balance. Applying equation 3 below, moisture content is determined.

Moisture content (M.C) $=\frac{W 2-W 3}{W 3-W 1} \times \frac{100}{1}$

$\mathrm{W}_{1}$ is weight of empty moisture can and its cover, $\mathrm{W}_{2}$ is weight of surface dried aggregate and moisture can, $\mathrm{W}_{3}, \mathrm{weight}$ of oven dried aggregate and moisture.

\subsubsection{Impact resistance test}

The apparatus for this test includes cylindrical measure, cylindrical cup, tamping rod, sieve size $1 / 2$ inch, $3 / 8$ inch and sieve no 7, weighing balance.

The impact resistance test was calculated as $\frac{W 2}{W 1} \times \frac{100}{1}--_{-} \quad-\quad-\quad 4$

$\mathrm{W}_{1}$ is the weight of the aggregate that was retained in 3/8 sieve. The aggregate was placed inside the cylindrical cup in 3 layers; each layer was tamped for 25 times. The cylindrical cup was placed inside the impact crushing machine and crushed for 15 times by $3 . W_{2}$ is the weight of aggregate that passes sieve no 7.

\subsection{Concrete Tests}

\subsubsection{Slump test}

Using slump cone, tamping rod, measuring tape, and weighing balance, each of the freshly prepared concrete was placed in 4 layers, each layer tamped 25 times with the tamping rod. $\mathrm{h}_{1}$ is weight the slump test mould, turned upside down and was removed from the concrete. $h_{2}$ is weight of free-standing concrete. The slump value was measured as the $h_{1}$ - $h_{2}$ expressed in $\mathrm{mm}$.

\subsubsection{Compressive strength test}

The compressive strength was determined using the procedure provided in ASTM [20] Standard Test Method for Compressive Strength of Cylindrical Concrete Specimens. Using compression testing machine, tamping rod, 150mm $\mathrm{x} 150 \mathrm{~mm} \times 150 \mathrm{~mm}$ cubical mould after 28 days of curing.

\subsubsection{Tensile splitting test}

Using compression testing machine, cylindrical mould and tamping rod, a well-mixed concrete was placed inside the cylindrical cube in two layers and each layer was well compacted. The specimen was then placed inside the curing tank for 28days. The wet specimen from water after 28 days of curing was wiped out water from surface of the specimen, the weight and dimension of the specimen was noted, the compression testing machine was set to the required range. A plywood strip was placed on the lower plate before placing the specimen. Another plywood strip was placed above the specimen, the load was applied continuously without shock at a rate of approximately $14-21 \mathrm{~kg} / \mathrm{cm}^{2} / \mathrm{minute}(\mathrm{which}$ corresponds to a total load of $9900 \mathrm{~kg} / \mathrm{minute}$ to the splitting $14850 \mathrm{~kg} /$ minute) and the breaking load was noted. 
Tensile strength was calculated using the formula TSP $=\frac{2 \mathrm{P}}{\Pi L D}$

Where $\mathrm{P}=$ applied load, $\mathrm{D}=$ diameter of the specimen, $\mathrm{L}=$ length of the specimen.

\section{Results and discussion}

\subsection{Fine aggregate}

A well rounded natural fine aggregate was tested, (river sand represented as NA-G-FA). Of the following test which includes bulk density and voids in aggregates, specific gravity, and absorption, moisture content and sieve analysis. The aggregate properties tests refer to the standardized ASTM tests performed on the materials. The results of this test were shown below.

\subsubsection{Sieve analysis of fine aggregate}

From the sieve analysis of natural fine aggregate (NA-A-FA) as shown in Fig. 1 below, the highest percent cumulative retained is in sieve No 200, while it passed $100 \%$ in No5, showing high level of uniformity in grain sizes.

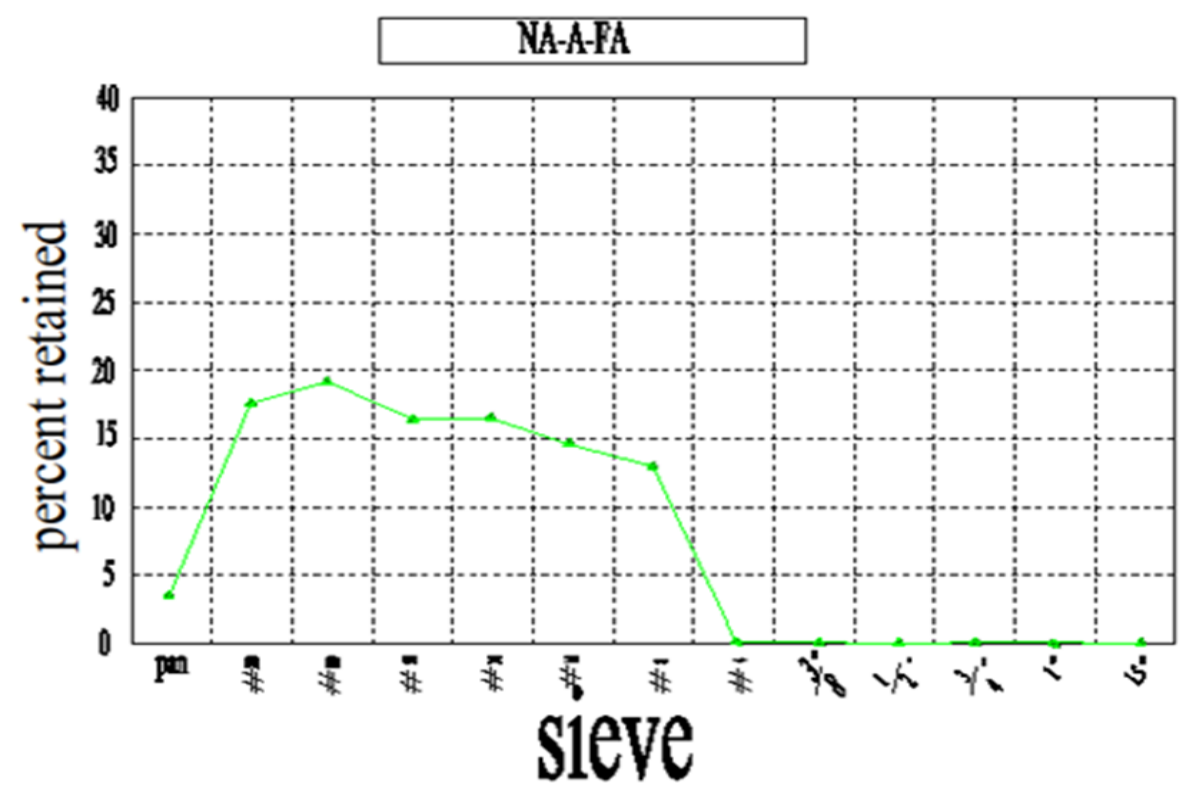

Figure 1 Graph of the Percent Retained of Sieve Analysis of the Fine Aggregate

\subsection{Coarse aggregates}

Two coarse aggregates were tested and used. The coarse aggregates (19mm maximum size) included a cubical, wellrounded natural coarse aggregate (NAT-A-CA) and a cubical, angular crushed granite coarse aggregate (GR-B-CA). The aggregate properties refer to the standardized ASTM tests performed on the materials, they include bulk density and voids in aggregates, specific gravity, and absorption, moisture content, sieve analysis, and impact resistance test. The result of this test is shown below.

\subsubsection{Sieve analysis of coarse aggregate}

Fig. 2 below shows the result of sieve analysis for coarse natural aggregate NA-A-CA and artificial aggregate GR-B-CA, the highest composition of the aggregate in GR-B-CA was observed in sieve 1/2" while in NA-A-CA had its highest at No.3/4. Generally, there was coarser component in both samples analyzed. 


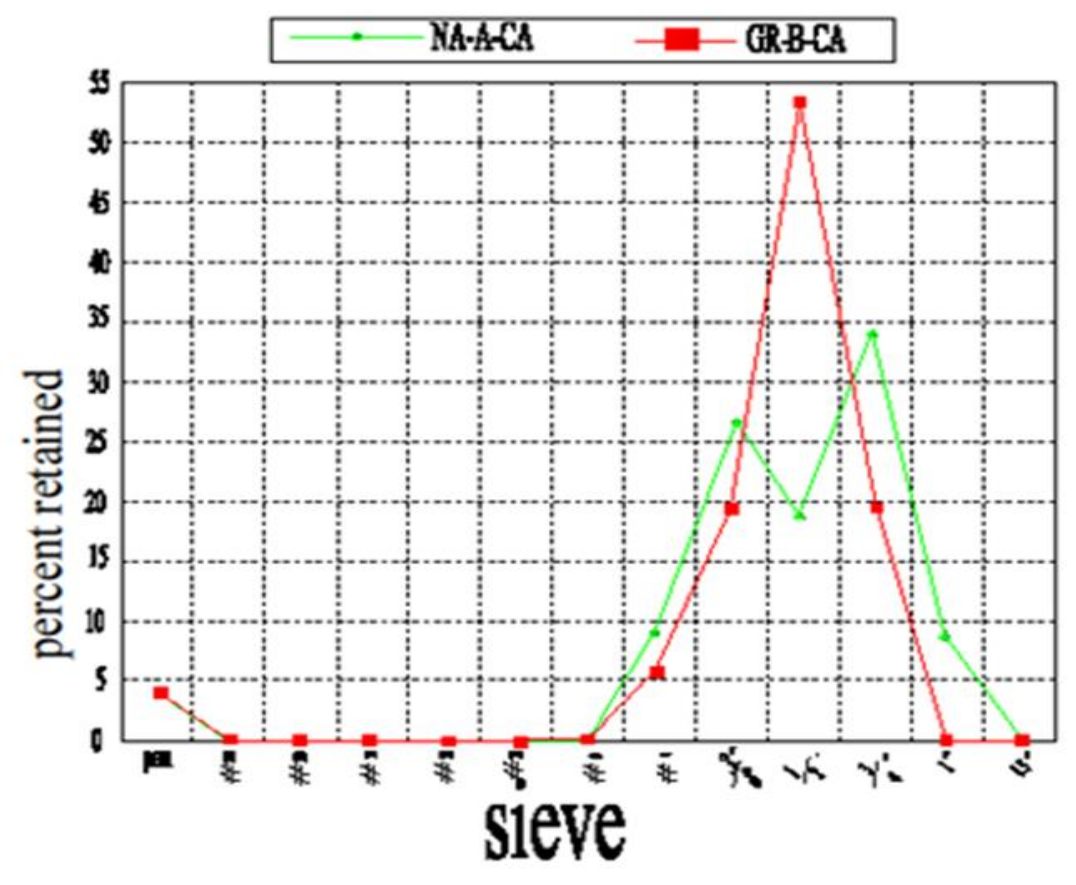

Figure 2 Graph of the Percent Retained in the Sieve Analysis of the NA-A-CA and GR-B-CA aggregate

\subsubsection{Summary of Aggregate Properties (NA-A-FA, NA-A-CA \& GR-B-CA)}

Table 1 shows the summary for the aggregate properties all the test samples. As expected, the coarse samples posted higher values for both specific gravity and impact resistance, while the fine sample had higher absorption capacity as well as bulk density. The moisture content was highest in GR-B-CA sample.

Table 1 Summary of Aggregate Properties

\begin{tabular}{|l|c|c|c|c|c|}
\hline Designation & $\begin{array}{l}\text { Specific } \\
\text { Gravity }\end{array}$ & $\begin{array}{l}\text { Absorption } \\
\text { Capacity }\end{array}$ & Bulk density & $\begin{array}{l}\text { Moisture } \\
\text { Content }\end{array}$ & $\begin{array}{l}\text { Impact } \\
\text { Resistace }\end{array}$ \\
\hline NA-A-FA & 2.4 & $27.6 \%$ & $1.7 \mathrm{~kg} / \mathrm{cm}^{3}$ & 0.5 & ------ \\
\hline NA-A-CA & 2.71 & $12.5 \%$ & $1.43 \mathrm{~kg} / \mathrm{cm}^{3}$ & 0.99 & $14.5 \%$ \\
\hline GR-B-CA & 2.67 & $13.4 \%$ & $1.33 \mathrm{~kg} / \mathrm{cm}^{3}$ & 3.8 & $11.5 \%$ \\
\hline
\end{tabular}

\subsection{Combined aggregate properties}

Three combinations of fine and coarse aggregates were blended to achieve three different gradings: with sand-toaggregate (S/A) ratios of $0.30,0.40$, and 0.50 . The aggregate combinations included NA-A-CA with NA-A-FA, GR-B-CA with NA-A-FA.

\subsubsection{Sieve analysis of $(N A-A-C A)+(N A-A-F A)$}

Fig. 3 below is a graph that shows the combined gradation for the different combinations of natural gravel (NA-A-CA) and the river sand (NA-A-FA). The curve corresponding to the $\mathrm{S} / \mathrm{A}=0.3$ gradation is the coarsest, while the gradation corresponding to $\mathrm{S} / \mathrm{A}=0.5$ has the highest amount of fine aggregates. Also the curve corresponding to $\mathrm{S} / \mathrm{A}=0.4 \mathrm{best}$ satisfy the Iowa DOT "18-8" Chart. 


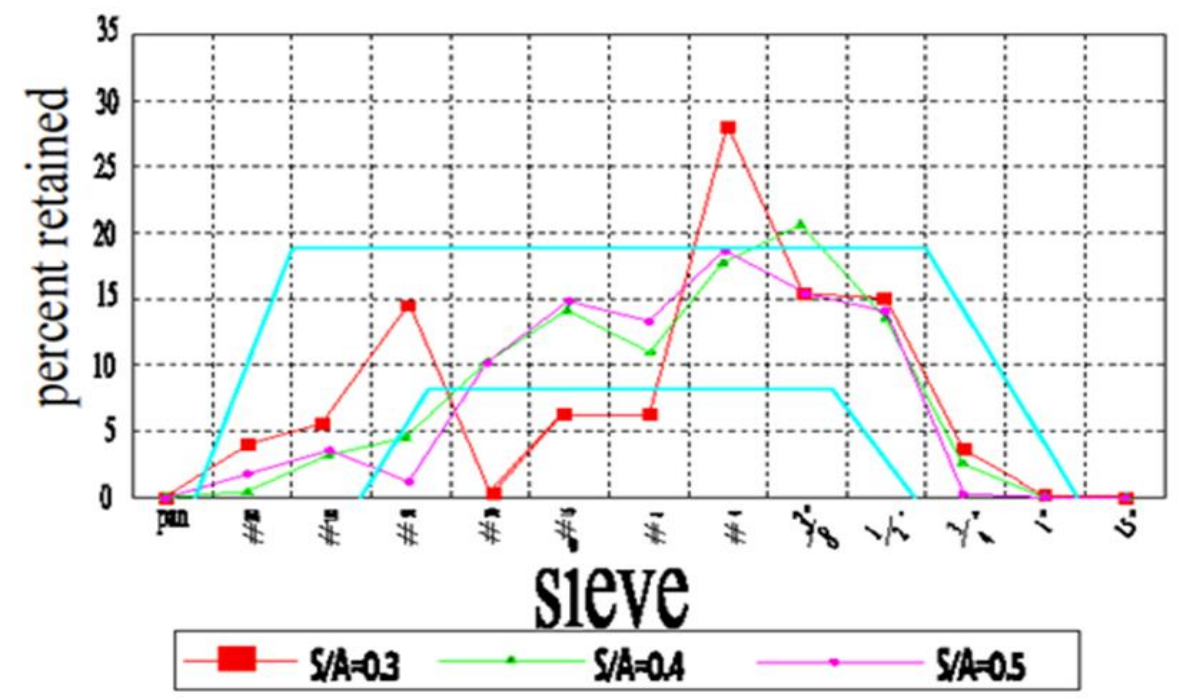

Figure 3 Graph of the Percent Retained in the Sieve Analysis of (NA-A-CA) + (NA-A-FA)

Fig. 4 shows the graph of percent passing for the sieve analysis of (NA-A-CA) + (NA-A-FA). The best combined gradation for those two aggregates is $\mathrm{S} / \mathrm{A}=0.4$; since it is the closest to the 0.45 power line. $\mathrm{S} / \mathrm{A}=0.3$ is too coarse (the curve is below the 0.45 power line) while $S / A=0.5$ is too fine (the curve is above the 0.45 power line).

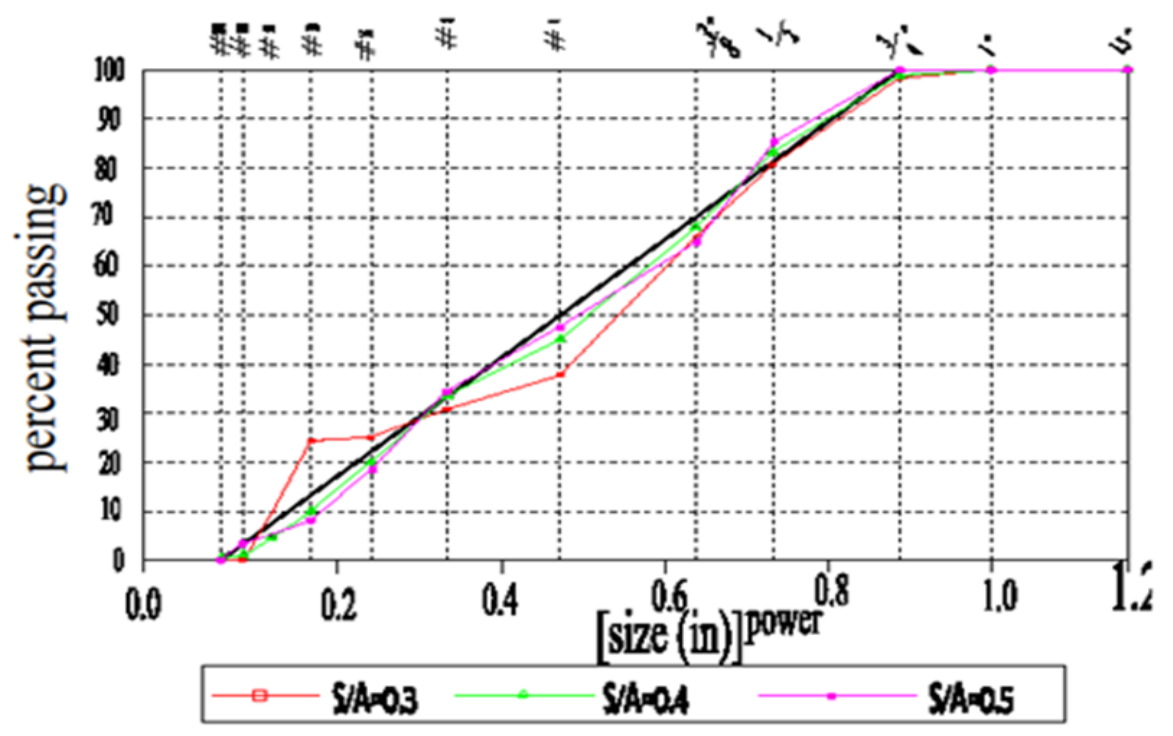

Figure 4 Graph of the Percent Passing in the Sieve Analysis of (NA-A-CA) + (NA-A-FA)

\subsubsection{Sieve Analysis of $(G R-B-C A)+(N A-A-F A)$}

The graph below, Fig. 5 shows the combined gradation for the different combinations of natural gravel (GR-B-CA) and the river sand (NA-A-FA). It was observed that the curve corresponding to the $S / A=0.3$ gradation is the coarsest, while the gradation corresponding to $\mathrm{S} / \mathrm{A}=0.5$ has the highest amount of fine aggregates. Also, the curve corresponding to $\mathrm{S} / \mathrm{A}=0.4$ best satisfy the Iowa dOT "18-8" Chart. 


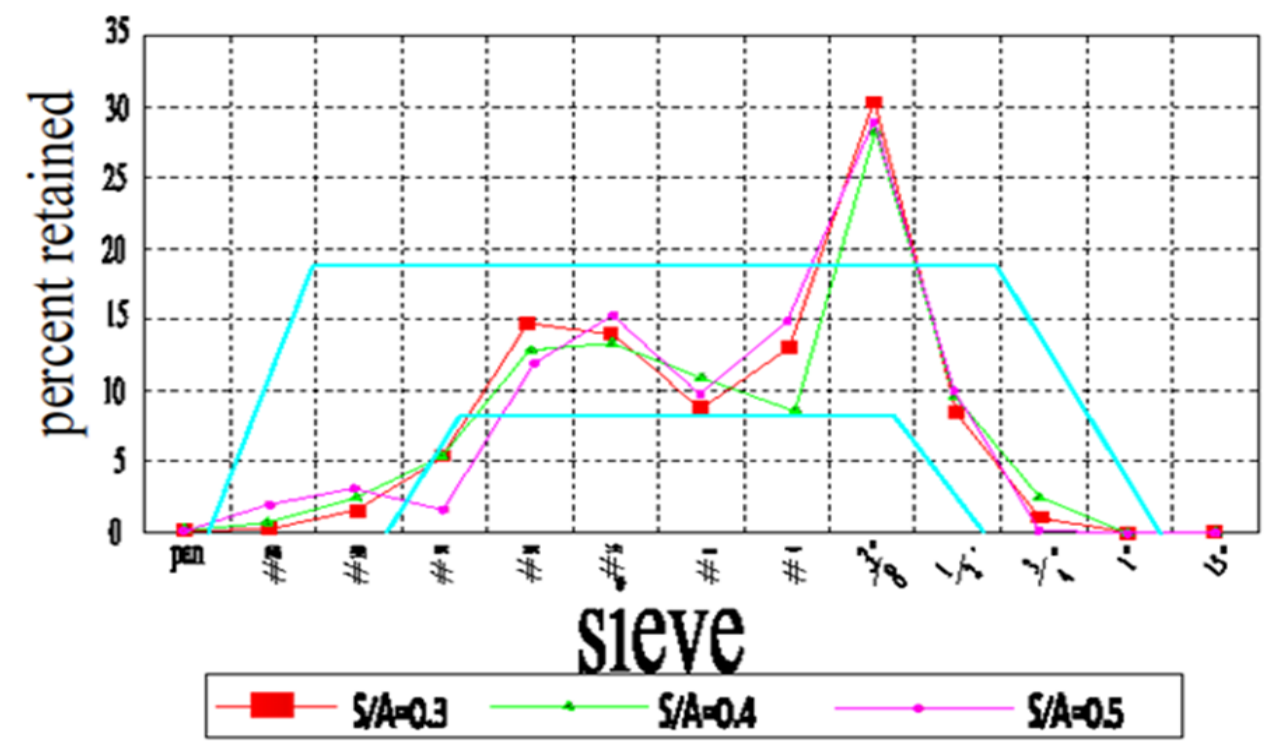

Figure 5 Graph of the Percent Retained in the Sieve Analysis of (GR-B-CA) + (NA-A-FA)

The best combined gradation as shown in Fig. 6 below, for the two aggregates is $\mathrm{S} / \mathrm{A}=0.4$; since it is the closest to the 0.45 power line. $\mathrm{S} / \mathrm{A}=0.3$ is too coarse (the curve is below the 0.45 power line) while $\mathrm{S} / \mathrm{A}=0.5$ is too fine (the curve is above the 0.45 power line).

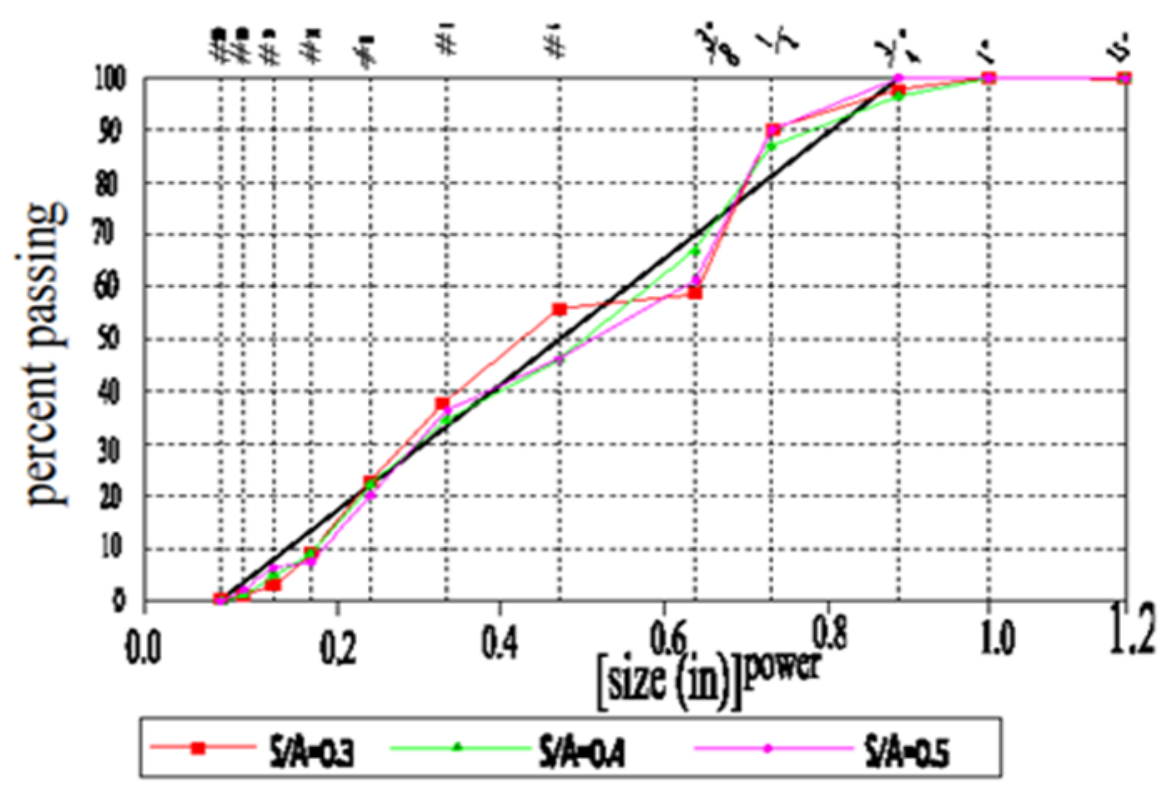

Figure 6 Graph of the Percent Passing in the Sieve Analysis of (GR-B-CA) + (NA-A-FA)

\subsubsection{Percentage Solids in Compacted Aggregate Blends}

Table 2 below shows from the mix of coarse and fine aggregate, it is observed that for all samples, the specific gravity and Bulk density almost the same. The percent solid is highest in the $\mathrm{S} / \mathrm{A}=0.5$ of GR-B-CA + NA-A-FA but lowest void percent and lowest in $\mathrm{S} / \mathrm{A}=0.3 \mathrm{GR}-\mathrm{B}-\mathrm{CA}+\mathrm{NA}-\mathrm{A}-\mathrm{FA}$ but highest void percent. 
Table 2 Percentage Solids and Voids in Compacted Aggregate Blends

\begin{tabular}{|c|c|c|c|c|c|c|}
\hline $\begin{array}{l}\text { Coarse } \\
\text { Aggregate ID }\end{array}$ & $\begin{array}{l}\text { Fine } \\
\text { Aggregate ID }\end{array}$ & S/A & Bulk Density & $\begin{array}{l}\text { Specific } \\
\text { Gravity }\end{array}$ & \% Solids & \% Voids \\
\hline NA-A-CA & NA-A-FA & 0.3 & $1.94 \mathrm{~kg} / \mathrm{cm}^{3}$ & 2.62 & 73.87 & 26.13 \\
\hline NA-A-CA & NA-A-FA & 0.4 & $1.93 \mathrm{~kg} / \mathrm{cm}^{3}$ & 2.59 & 74.65 & 25.35 \\
\hline NA-A-CA & NA-A-FA & 0.5 & $1.93 \mathrm{~kg} / \mathrm{cm}^{3}$ & 2.56 & 75.51 & 24.49 \\
\hline GR-B-CA & NA-A-FA & 0.3 & $1.87 \mathrm{~kg} / \mathrm{cm}^{3}$ & 2.59 & 72.30 & 27.70 \\
\hline GR-B-CA & NA-A-FA & 0.4 & $1.91 \mathrm{~kg} / \mathrm{cm}^{3}$ & 2.56 & 74.44 & 25.56 \\
\hline GR-B-CA & NA-A-FA & 0.5 & $1.94 \mathrm{~kg} / \mathrm{cm}^{3}$ & 2.54 & 76.28 & 23.72 \\
\hline
\end{tabular}

The table 3 below contains the weight values of different combinations of aggregate. For each $S / A$ ratio the percent solids and percent voids were computed. Those values aid in the estimation of minimum percent paste for concrete as shown.

Table 3 Aggregate Mix for Design of the Concrete

\begin{tabular}{|c|c|c|c|c|c|c|c|c|c|}
\hline Coarse & Fine & $\frac{\mathbf{S}}{\mathbf{A}}$ & $\begin{array}{c}\mathbf{A g g} \\
\mathbf{m}^{3}\end{array}$ & $\begin{array}{c}\text { Paste } \\
\mathbf{m}^{3}\end{array}$ & $\begin{array}{c}\text { Agg } \\
\mathbf{K g}\end{array}$ & $\begin{array}{c}\text { Coarse } \\
\mathbf{K g}\end{array}$ & $\begin{array}{c}\text { Fine } \\
\text { Kg }\end{array}$ & $\begin{array}{c}\text { Cement } \\
\text { Kg }\end{array}$ & $\begin{array}{c}\text { Water } \\
\text { Kg }\end{array}$ \\
\hline NA-A-CA & NA-A-FA & 0.3 & 0.0217 & 0.0077 & 56.830 & 39.780 & 17.048 & 3.85 & 3.85 \\
\hline NA-A-CA & NA-A-FA & 0.4 & 0.0219 & 0.0074 & 56.731 & 34.035 & 22.690 & 3.7 & 3.7 \\
\hline NA-A-CA & NA-A-FA & 0.5 & 0.0221 & 0.0072 & 56.611 & 28.306 & 28.306 & 3.6 & 3.6 \\
\hline GR-B-CA & NA-A-FA & 0.3 & 0.0212 & 0.0082 & 54.900 & 38.427 & 16.469 & 4.1 & 4.1 \\
\hline GR-B-CA & NA-A-FA & 0.4 & 0.0219 & 0.0075 & 55.888 & 33.532 & 22.355 & 3.75 & 3.75 \\
\hline GR-B-CA & NA-A-FA & 0.5 & 0.0224 & 0.0070 & 56.888 & 28.443 & 28.443 & 3.5 & 3.5 \\
\hline
\end{tabular}

From the cement content mix in Fig. 7 below, it was observed that the aggregate combination of GR-B-CA+NA-A-FA at $S / A=0.3$ in the design demands highest quantity of cement while the least cement and water demand was seen in GR-B$\mathrm{CA}+\mathrm{NA}-\mathrm{A}-\mathrm{FA}$ at $\mathrm{S} / \mathrm{A}=0.5$. It was also noted all NA-A-CA mix had relative low cement demand.

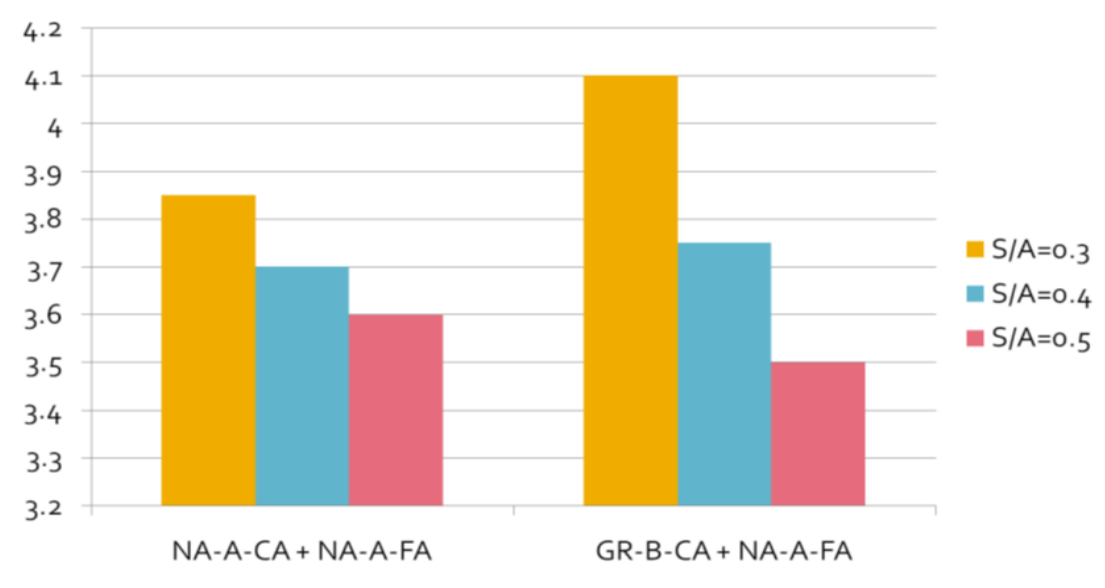

Figure 7 COMPARING CEMENT CONTENT (Kg) OF THE MIX DESIGN 


\subsection{Concrete properties}

\subsubsection{Compressive strength test}

The highest strength was observed in GRA-B-CA+NA-A-FA mix at S/A= 4.0, though all mix of GRA-B-CA showed higher strength at all S/A than as observed in NA-A-CA mix as shown in Fig. 8.

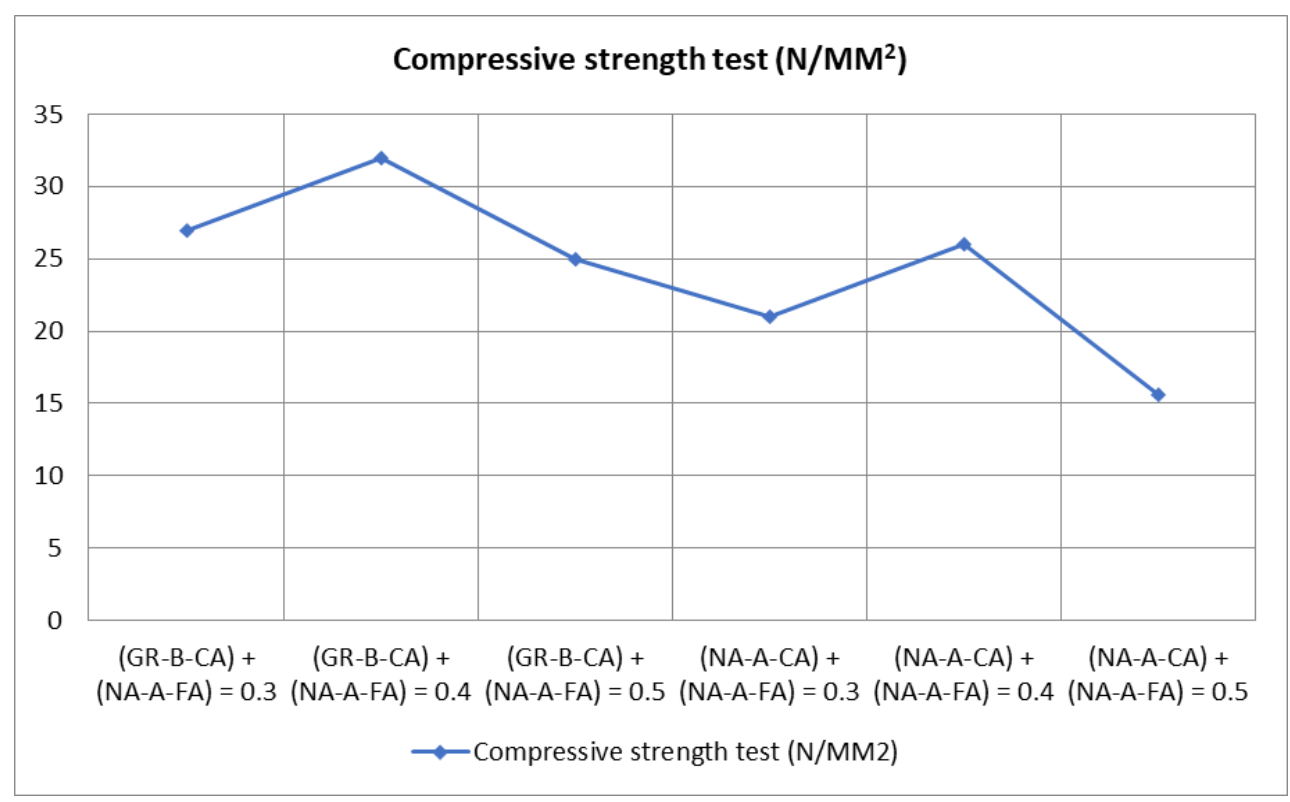

Figure 8 Result of compressive strength test

\subsubsection{Tensile splitting test}

This test was conducted after 28days of curing, three cylinders of concrete were casted for each mixing ratio, and then the tensile splitting test was carried out in all of them and average result was tabulated in table 4 below, it can be observed that the breaking load and splitting strength was highest for $\mathrm{S} / \mathrm{A}=0.4 \mathrm{GR}-\mathrm{B}-\mathrm{CA}$ mix. While the lowest was observed in $\mathrm{S} / \mathrm{A}=0.5 \mathrm{NA}-\mathrm{A}-\mathrm{CA}$ mix.

Table 4 Result of tensile strength test

\begin{tabular}{|c|c|c|c|c|}
\hline ID No. & $\begin{array}{l}\text { Dia of the } \\
\text { specimen }(\mathrm{mm})\end{array}$ & $\begin{array}{l}\text { Length of the } \\
\text { specimen (mm) }\end{array}$ & $\begin{array}{l}\text { Breaking load } \\
\text { (kg force) }\end{array}$ & $\begin{array}{l}\text { Splitting } \\
\text { Strength (MPa) }\end{array}$ \\
\hline$(\mathrm{NA}-\mathrm{A}-\mathrm{CA})+(\mathrm{NA}-\mathrm{A}-\mathrm{FA})=0.3$ & 100 & 200 & 8,000 & 2.55 \\
\hline$(\mathrm{NA}-\mathrm{A}-\mathrm{CA})+(\mathrm{NA}-\mathrm{A}-\mathrm{FA})=0.4$ & 100 & 200 & 7,600 & 2.42 \\
\hline$(\mathrm{NA}-\mathrm{A}-\mathrm{CA})+(\mathrm{NA}-\mathrm{A}-\mathrm{FA})=0.5$ & 100 & 200 & 6,000 & 1.91 \\
\hline$(\mathrm{GR}-\mathrm{B}-\mathrm{CA})+(\mathrm{NA}-\mathrm{A}-\mathrm{FA})=0.3$ & 100 & 200 & 9,500 & 3.02 \\
\hline$(\mathrm{GR}-\mathrm{B}-\mathrm{CA})+(\mathrm{NA}-\mathrm{A}-\mathrm{FA})=0.4$ & 100 & 200 & $11^{\prime} 300$ & 3.60 \\
\hline$(\mathrm{GR}-\mathrm{B}-\mathrm{CA})+(\mathrm{NA}-\mathrm{A}-\mathrm{FA})=0.5$ & 100 & 200 & 7,900 & 2.51 \\
\hline
\end{tabular}

\section{Conclusion}

The results obtained in this research confirm that aggregate type and gradation can play an important role in getting optimum cement content of concrete mixtures. It can be concluded that from aggregate properties analyzed, $\mathrm{S} / \mathrm{A}=0.4$ for GR-A-CA, holds optimum qualities and workability. It was also observed that improving the aggregate shape and grading allowed a reduction in paste volume while maintaining workability and hardened properties. Aggregates with 
angular shape resulted in increased paste volume and reduced workability. Aggregates with coarser grading are generally more workable but requires higher paste volume to ensure adequate cohesiveness.

\section{Compliance with ethical standards}

\section{Acknowledgments}

The first and second authors acknowledge the support of the Department of Civil Engineering, University of Nigeria for availing us the enabling environment to conduct this research.

\section{Disclosure of conflict of interest}

The authors declare that there is no conflict of interest in the preparation and submission of this paper.

\section{References}

[1] Collivignarelli MC, Cillari G, Ricciardi P, Miino MC, Torretta V, Rada EC, Abbà A. The Production of Sustainable Concrete with the Use of Alternative Aggregates: A Review. Sustainability. 2020; 12: 7903.

[2] Rached M, De Moya M, Fowler DW. Utilizing Aggregates Characteristics to Minimize Cement Content in Portland Cement Concrete. International Center for Aggregates Research Report 401, Austin, TX. 2009.

[3] Hudson B. Modification to the Fine Aggregate Angularity Test, Proceedings, Seventh Annual International Center for Aggregates Research Symposium, Austin, TX. 1999.

[4] Portland Cement Association (PCA). Cement \& Concrete Basics. www.cement.org/cement-concrete-basics/howcementismade retrieved on 20-05-2014.

[5] Lopera HC, Vélez JM, Montoya MC. Aggregate particle size interrelations and case study in concrete using white ordinary Portland cement. Informador técnico. 2000; 84(2): 114-132.

[6] Arivalagan S, Sethuraman VS. Experimental study on the mechanical properties of concrete by partial replacement of glass powder as fine aggregate: An environmentally friendly approach. Materials Today: Proceedings. 2020; 45(7): 6035-6041.

[7] Quiroga PN, Fowler DW. The Effects of Aggregates Characteristics on The Performance of Portland Cement Concrete. International Center for Aggregates Research Report 104, Austin, TX. 2004.

[8] Legg FE Jr. Aggregates, Chapter 2, Concrete Construction Handbook, ed. Dobrowolski, J. McGraw-Hill. 4th ed. 1998.

[9] Shilstone JM Sr. Concrete Mixture Optimization, Concrete International: Design and Construction. 1990; 12(6): 33-39.

[10] Shilstone JM. The Aggregate: The Most Important Value-Adding Component in Concrete, Proceedings, Seventh Annual International Center for Aggregates Research Symposium, Austin, Texas. 1999.

[11] Dewar JD, Anderson R. Manual of Ready-Mixed Concrete, Blackie Academic and Professional, 2nd ed., London. Farmington Hills, MI: American Concrete Institute. 1992; 77.ACI Committee 302. ACI 302.1R: Guide for Concrete Floor and Slab Construction. 2004.

[12] Kaplan MF. Flexural and Compressive Strength of Concrete as Affected by the Properties of Coarse Aggregates, Proceedings, American Concrete Institute. 1959; 55: 1193-1208.

[13] ASTM C 33. Standard Specification for Concrete Aggregates, American Society for Testing and Materials, Philadelphia, PA. 2003.

[14] Lafrenz JL. Aggregate Grading Control for PCC Pavements: Improving Constructability of Concrete Pavements by Assuring Consistency of Mixes, Proceedings, Fifth Annual International Center for Aggregates Research Symposium, Austin, Texas. 1997.

[15] Koehler EP, Fowler DW. Aggregates in Self Consolidating Concrete. International Center for Aggregates Research Report 108-2F, Austin, TX. 2007.

[16] ASTM C 136. Standard Test Method for Sieve Analysis of Fine and Coarse Aggregates, American Society for Testing and Materials, Philadelphia, PA. 2001. 
[17] ASTM C 127. Standard Test Method for Specific Gravity and Absorption of Coarse Aggregate, American Society for Testing and Materials, Philadelphia, PA. 2001.

[18] ASTM C 128. Standard Test Method for Specific Gravity and Absorption of Fine Aggregate, American Society for Testing and Materials, Philadelphia, PA. 2001.

[19] ASTM C 29. Test Method for Bulk Density ("Unit Weight") and Voids in Aggregate, American Society for Testing and Materials, Philadelphia, PA. 1997.

[20] ASTM C 39. Standard Specification for Concrete Aggregates, American Society for Testing and Materials, Philadelphia, PA. 2003. 